\title{
La educación ambiental y la conservación del patrimonio natural en el litoral costasoleño con dunas
}

Susanne Stamm Joho | Asociación ProDunas Marbella

URL de la contribución <www.iaph.es/revistaph/index.php/revistaph/article/view/3962>

\section{RESUMEN}

La Costa del Sol occidental, centrada en torno a la ciudad de Marbella, es uno de los enclaves turísticos más importantes de España e incluso de Europa, y uno de sus ecosistemas más destacados es el gran cordón dunar marbellí.

Lamentablemente se encuentra en peligro por el extraordinario desarrollo urbanístico que ha sufrido la zona; desde el año 2004, un grupo de marbellíes intenta recuperar, rehabilitar y preservar nueve vestigios dunares a través de la Asociación sin ánimo de lucro Pro Dunas.

\section{Palabras clave}

Asociación Pro-dunas | Costa del Sol | Dunas | Ecosistema | Marbella (Málaga) | 


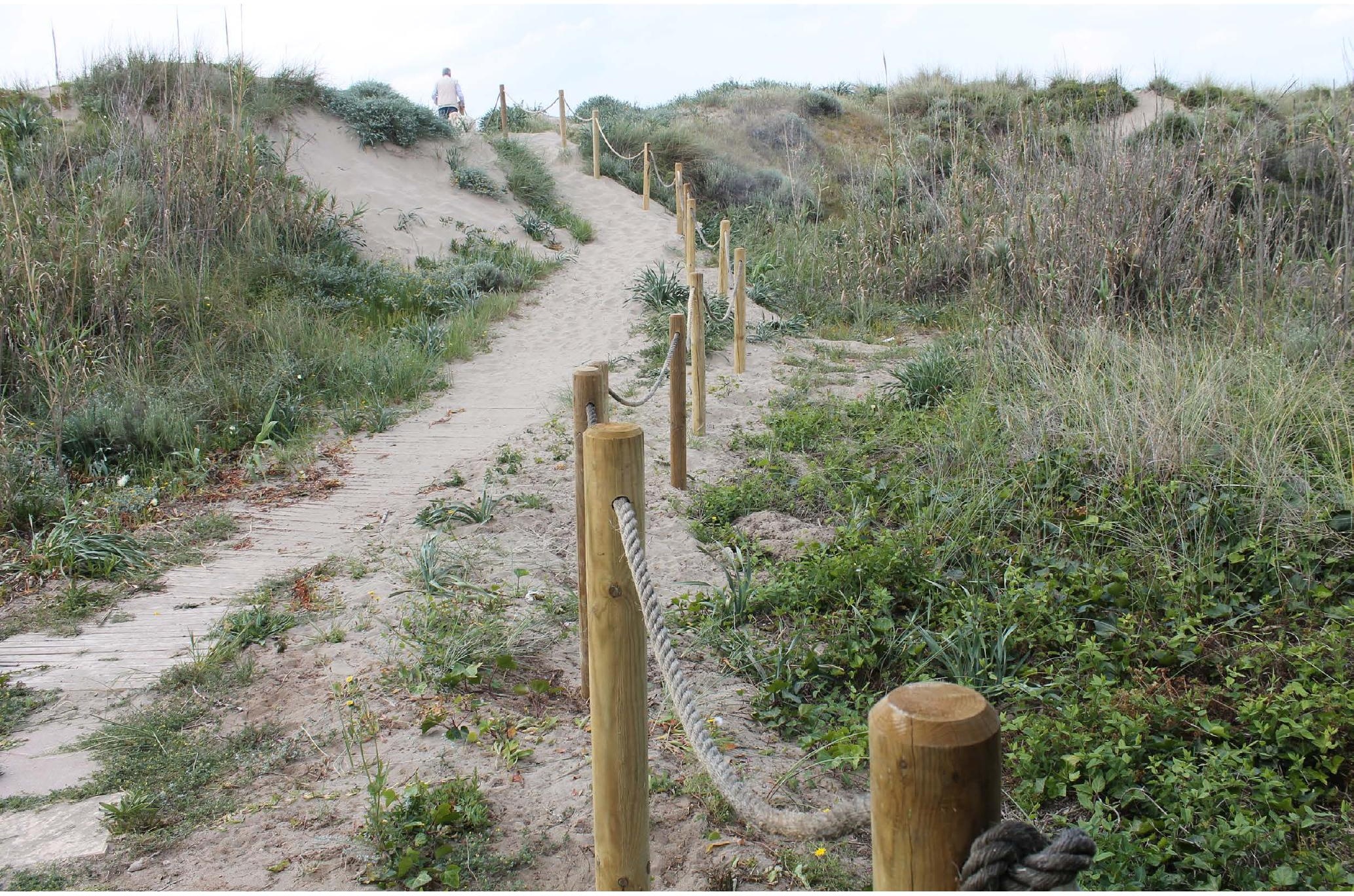

Colocación de estacas concatenadas en su duna apadrinada. English Intern. College, Elviria | foto ProDunas, fuente de todas las imágenes del artículo si no se indica lo contrario 
1

Web: www.produnas.org;

Correo-e.: asociacion@produnas.org

Uno de los ecosistemas originales más destacados de la Costa del sol occidental era sin duda el gran cordón dunar marbelí, con la particularidad además de contar con las últimas influencias atlánticas, en el aspecto ecológico, en un litoral ya mediterráneo. La originaria formación de las dunas es aún hoy formidablemente visible en todos los tramos dunares comprendidos entre el este de Marbella y Cabopino.

Lamentablemente la contrapartida de un desarrollo urbanístico extraordinario en las últimas décadas ha conllevado de manera generalizada una feroz destrucción de los ecosistemas litorales originales, de los que actualmente, intactos, solo quedan nueve entornos que albergan dunas, y que son interrumpidos por urbanizaciones a lo largo de 13 km, desde la de Río Real hasta Elviria.

Es importante señalar que en el año 2004 un grupo de marbellíes, españoles y de origen foráneo, fundaron la Asociación Pro Dunas ${ }^{1}$ (sin ánimo de lucro) para recuperar, rehabilitar y preservar estos nueve vestigios dunares. Durante años se han dedicado a las tareas de erradicación de especies exóticas invasoras a través de programas de participación ciudadana y, con ayuda de escolares, se han podido reforestar varios enclaves dunares. Los plantones los proporcionaba la Delegación territorial de Medio Ambiente y de Ordenación del Territorio, y grupos de voluntarios de la asociación se encargaban de los riegos semanales de cada uno de los plantones, labor que se ha llevado a cabo durante dos años consecutivos.

Educación ambiental para 100 escolares, una introducción sobre la erradicación de especies invasoras. CEIP Valdeolletas, Marbella

Aspandem, centro ocupacional y de jardinería jornada de erradicación de la margarita africana en su duna apadrinada

El deseo de la Asociación era que cada uno de los nueve entornos dunares recibiera la protección apropiada, y para ello se presentó una memoria técnica a la Junta de Andalucía, impulsando la preservación de dichos ecosistemas. A finales del año 2015, la dedicación de tantos años dio su frutos. Las nueve
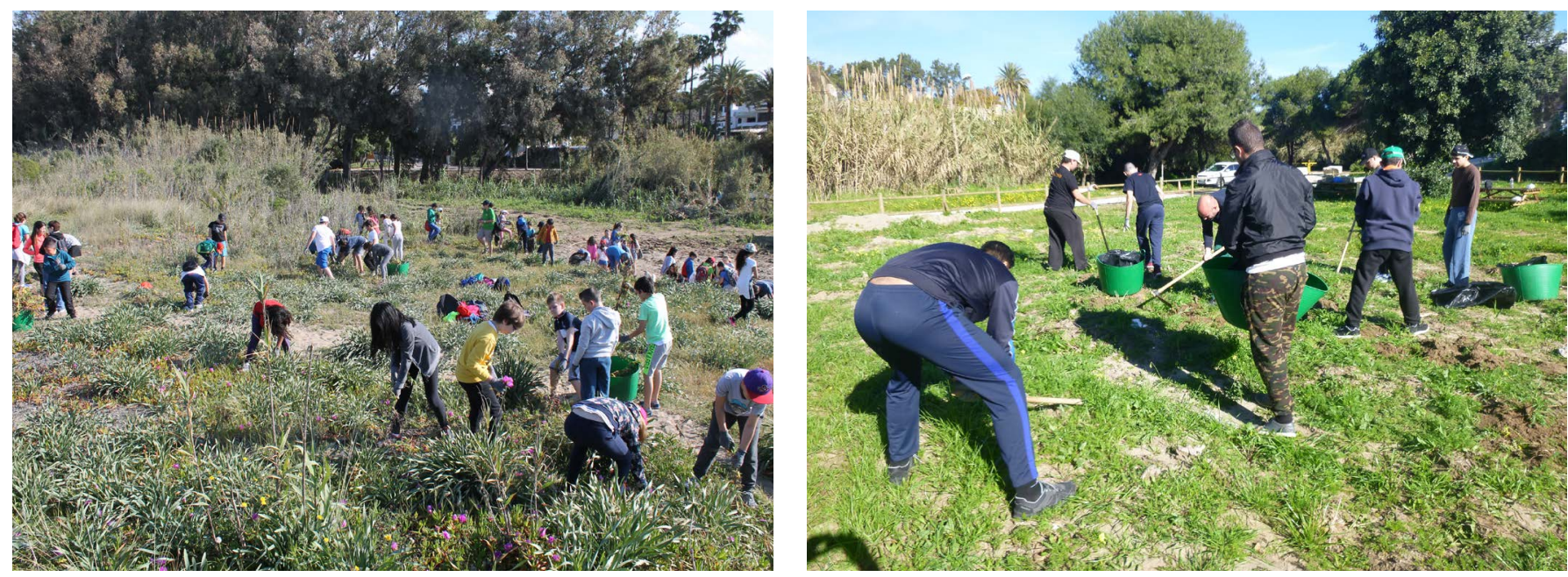
zonas dunares fueron declaradas reserva ecológica-dunas de Marbella por parte de la Consejería de MedioAmbientey Ordenación del Territorio de la Junta de Andalucía. El art. 11 del Decreto 23/2012 de 14 de febrero regula la conservación y el uso sostenible de la flora y fauna silvestre y sus hábitats. El mérito de la Asociación Pro Dunas ya es visible: $220.000 \mathrm{~m}^{2}$ de ecosistemas dunares protegidos a lo largo de $13 \mathrm{~km}$. En este contexto hay que resaltar el factor imprescindible para los logros alcanzados: la participación ciudadana, el importante eslabón que en esta cadena constituye cada persona voluntaria, y su implicación altruista que posibilita la programación de actividades medioambientales.

No se debe olvidar la otra extensión significativa del cordón marbellí que se ubica en Cabopino. En el año 2003 estas dunas, que han podido sobrevivir a las presiones urbanísticas, han sido declaradas Monumento Natural "Dunas de Artola" por la Junta de Andalucía. Este monumento natural abarca unos $210.000 \mathrm{~m}^{2}$ de superficie, formando la frontera entre los términos municipales de Marbella y de Mijas. Existe una excepcional vegetación autóctona: pinos piñoneros centenarios (Pinus pinea) e importante desarrollo de sabinas (Juniperus phoenicea subsp. turbinata), algún alcornoque (Quercus suber), así como lentiscos (Pistacia lentiscus) y varios ejemplares de Acebuche (Olea europea var.sylvestris). El bajo bosque se compone de una variada flora arbustiva leñosa y delicada flora autóctona. Lo significativo es que este entorno natural ha podido mantenerse intacto con vegetación autóctona y casi nula aparición de especies exóticas invasoras, a pesar de la gran presión humana que también ha sufrido.

Así pues Pro Dunas está comprometida con el mantenimiento y conservación manual de unos $500.000 \mathrm{~m}^{2}$ de ecosistema dunar entre la Reserva EcológicaDunas de Marbella y el Monumento Natural "Dunas de Artola" en Cabopino.
Jornada de erradicación. Escolares de primaria en su duna apadrinada La Víbora. CEIP Platero, Elviria

Duna La Víbora, Elviria. Voluntariado Pro Dunas
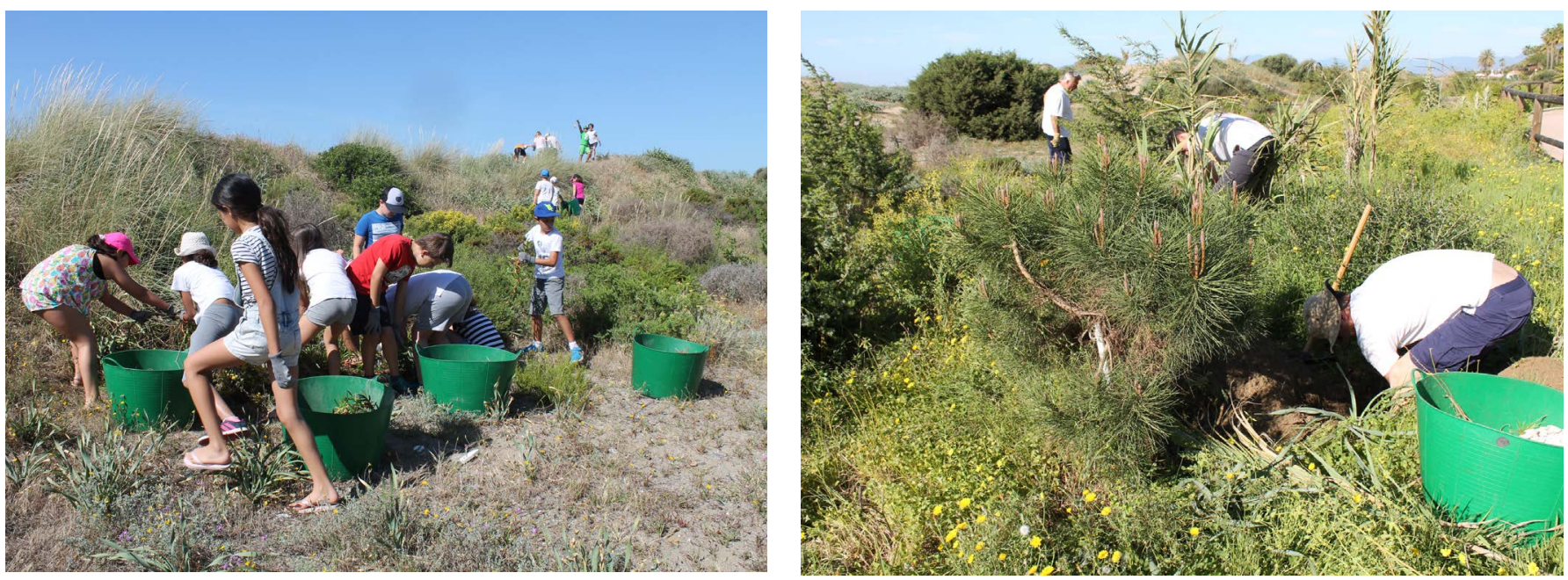

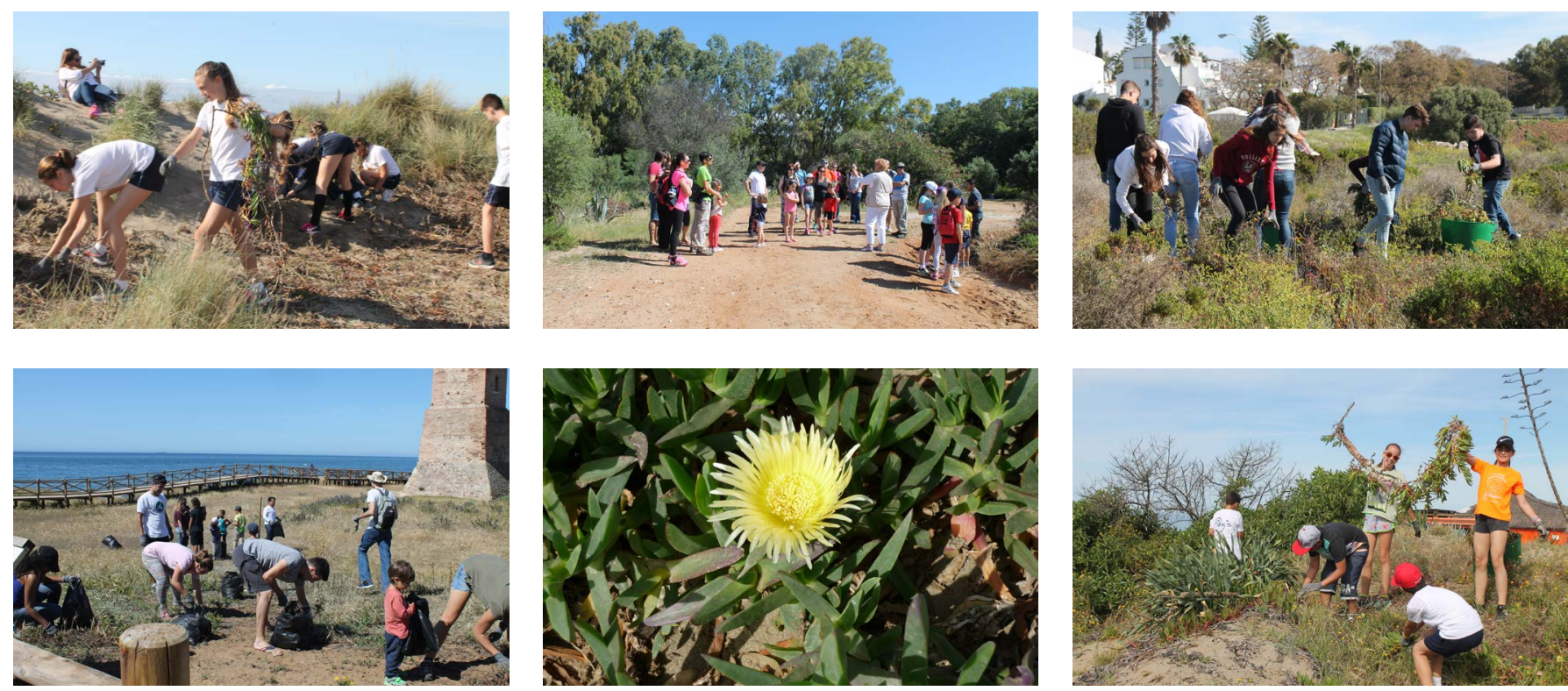

De izquierda a derecha de arriba a abajo:

Alumnos del Colegio Alemán Juan Hoffmann, Elviria. Jornada de erradicación de la uña de gato en la duna del Real de Zaragoza;

Educación ambiental en la duna del Real de Zaragoza. Grupo de familias;

Jornada de erradicación en Real de Zaragoza. IES Dunas de las Chapas, Elviria;

Una tonelada de uña de gato erradicada. IES Dunas de las Chapas, Elviria

Uña de gato (Carpobrotus edulis). Proliferación de la especie en el litoral costasoleño;

Jornada de erradicación en su duna, en Real de Zaragoza. Alumnos del CEIP Juan Ramón Jiménez, Marbella

\section{EDUCACIÓN Y SENSIBILIZACIÓN AMBIENTAL}

En el año 2013 la asociación vio la necesidad de involucrar a más grupos humanos en la conservación de tantos entornos dunares. Una de las iniciativas más innovadoras de las que se iniciaron en ese momento fue el apadrinamiento dunar por escolares. Con esta apuesta se ha conseguido que doce centros escolares se involucren anualmente para que los alumnos trabajen en grupo. ProDunas intenta concienciarlos de que serán ellos mismos los encargados de transmitir la enorme biodiversidad existente en estos ecosistemas del litoral costasoleño. $Y$ los escolares adquieren el compromiso con el lema "1 semilla = 1 planta autóctona".

Las estadísticas anuales (21 jornadas y 1.146 participantes en 2016; y 29 jornadas y 1.059 participantes en el primer semestre de 2017) demuestran el creciente éxito de participación, e impulsa la continuidad de los programas educativos de sensibilización.

Las actividades que se llevan a cabo en los ecosistemas dunares encaminadas a la educación ambiental se desarrollan mediante la interpretación del medio natural, y la experiencia que tiene lugar en el mismo.

Se organizan recorridos interpretativos por las zonas dunares del término de Marbella, que poseen un alto valor ecológico y son únicas en toda la provincia de Málaga. Durante los paseos se fomenta la atención a los cinco sentidos, hacendo hincapié en "lo próximo", de manera que se aprenda a "ver" con nuevos ojos el espacio que antes solo se usaba para pasear o para bañarse. 

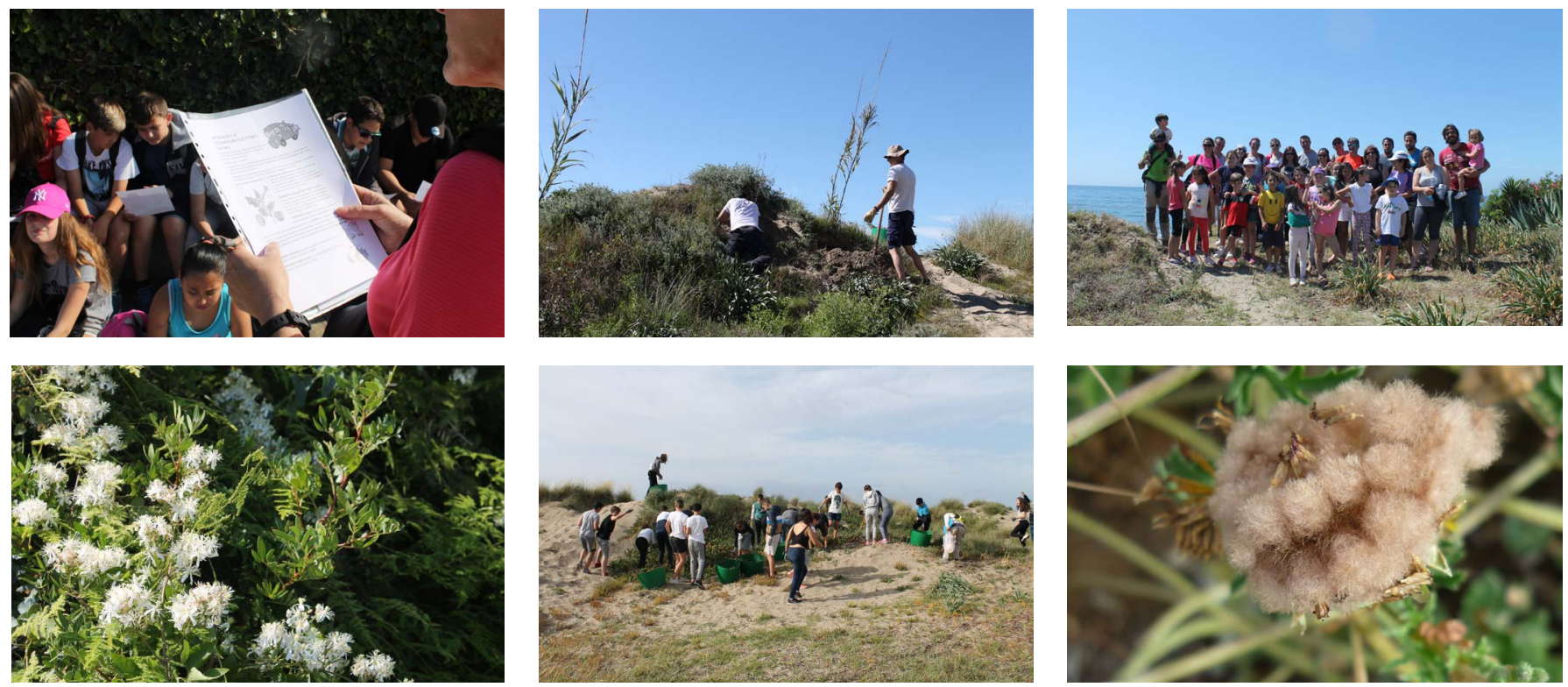

De izquierda a derecha de arriba a abajo:

Enseñanza didáctica a pie de duna apadrinada. IES Sierra Blanca, Marbella;

Del mismo modo, con las actividades de conservación dunar con erradicación de especies exóticas invasoras (Carpobrotus edulis -uña de gatoo Arctotheca calendula -margarita africana-), o las de identificación de la flora autóctona en entornos dunares (con activo apoyo del profesorado) también se conciencia al alumnado de su responsabilidad en la conservación de estos ecosistemas.

Duna La Víbora, Elviria. Voluntariado Pro Dunas descepando caña (Arundo donax);

Jornada de enseñanza a los padres y madres de cómo se erradica una especie exótica invasora Asociación AMPA del CEIP Juan Ramón Jiménez, Marbella;

Mirto (Myrtus communis). Monumento Natural Dunas de Artola, Cabopino;

Jornada de colaboración y erradicación en Real de Zaragoza. IES Guadalpín, Marbella;

Semilla de margarita africana (Arctotheca calendula). Monumento Natural Dunas de Artola, Cabopino 